\title{
CHARACTERIZATION OF HISTORIC MORTARS FOR COMPATIBLE RESTORATION: CASE STUDY OF SOUTH AFRICA
}

\author{
Maphole E. Loke ${ }^{1 *}$, Kumar Pallav ${ }^{2}$ and Rainer Haldenwang ${ }^{3}$ \\ ${ }^{1}$ Department of Civil Engineering \& Surveying, Cape Peninsula University of Technology \\ Bellville main campus, 7535 Cape Town, South Africa \\ e-mail: lokemaphole@gmail.com,www.cput.ac.za (*corresponding author) \\ ${ }^{2}$ Department of Civil Engineering \& Surveying, Cape Peninsula University of Technology \\ Bellville main campus, 7535 Cape Town, South Africa \\ e-mail: \{kumarp@cput.ac.za, haldenwangr@cput.ac.za\}www.cput.ac.za
}

Keywords: Historical Structures, Mortar characterization, Compatibility, Restoration

\begin{abstract}
The history of the South African construction industry dates as far back as the Castle of Good Hope (1666), Slave Lodge (1679), Robben Island (1700), Union Buildings (1913), memorials and cathedrals, among many others. These structures represent the political, slavery, liberation and religious history of South Africa and its development throughout the years, while also contributing towards economic growth through tourism. Historical buildings stand out from the rest of the modern constructions as they portray marvellous architectural designs and unique materials used for their construction. However, due to ageing and environmental conditions, they often show critical signs of deterioration, which threaten the existence of some. In attempts to rescue these national treasures, the use of Portland cement, which is considered incompatible with the original materials, has become a common practice, not only in South Africa but abroad. To avoid disparity in materials during repair of historic structures, original material characterization is therefore recommended. This paper investigates the effects of Portland cement used on the repairs of historical masonries of the Castle of Good Hope, Cape Town and buildings on Robben Island, in South Africa. The mortar samples were collected from the Castle and analyzed using the techniques such as the visual investigation, cohesion test, microscopic and titration test. It is observed that the original limebased mortars are not compatible with the Portland cement produced mortars. It was evident on the masonry, as the repairs are repelling from the original surfaces on these two structures.
\end{abstract}




\section{INTRODUCTION}

Historical buildings deteriorate with apparent signs of material failure which is caused by several factors that include the following: Ageing of the structure, human negligence and ignorance, high humidity and rainfall, temperature changes due to seasonal changes and drastic fluctuations in day and night temperatures, atmospheric moisture, exposure to soluble salts, air pollution, chemical processes and biological attack by plants and animals ${ }^{[1]}$. Despite the factors outlined above, the durability of historic buildings depends on their regular maintenance. It is of obvious benefit that defects are prevented beforehand. However, regular maintenance with incompatible materials is equally discouraged. If these heritage legacies are not properly maintained, the economy suffers because of repeated repairs and loss of authenticity during restoration, which causes a reduction in tourist traffic. Hence, their protection with proper maintenance and use of compatible materials needs to be prioritized to ensure their continued existence and functionality.

The repair and restoration of heritage structures is a major challenge, as most of these buildings were built using materials that have been superseded by modern construction materials. The overall challenge is incorporating the old mortars (of unknown properties) with new materials, to solve the problem of decay. The challenge is a result of the availability of many new materials caused by growth in the construction industry in recent years. As a result, the construction industry opts for modern construction materials to solve the decay problems associated with historical structures. The typical procedure for restoration of ancient lime-based mortars is through the the problem ${ }^{[2]}$. The negative repercussions the case ${ }^{[3]}$

The properties of Portland cement differ

causing reactions and acceleration of defects ${ }^{[2]}$. The application of Portland cement-based
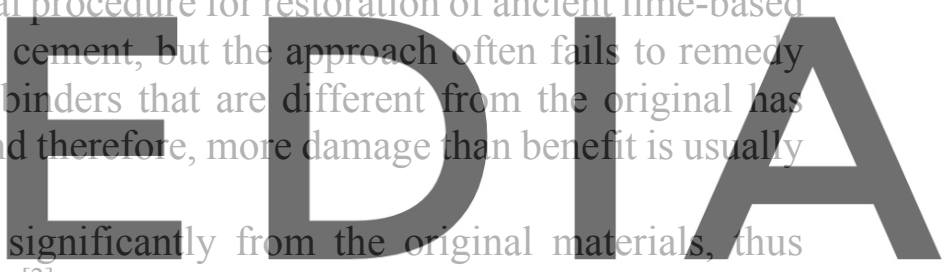

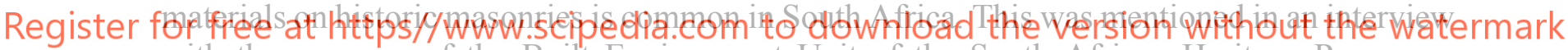
with the manager of the Built Environment Unit of the South African Heritage Resources Agency (SAHRA). He stated that during the most heritage building maintenance projects in

South Africa, the common practice is the replacement of the original material with Portland cement ${ }^{[4]}$.

The failure of Portland cement-based mortar when repairing structures where historic limebased mortars were used is due to the difference in properties of Portland cement when compared with most of the ancient materials (lime in particular). Therefore, the substitution of original materials with Portland cement intensifies damage to the original fibers in the mortar, hence, causing deterioration of the masonry.

The current lack of understanding of the original material behavior has seen several restoration projects result in disaster. Most researchers fail to understand the concept of compatibility when it comes to restoration of historic mortars ${ }^{[5]}$. For developing countries such as South Africa, this approach has undoubtedly impacted negatively on the economy, as repeated repairs have been necessary in the case of the re-pointing and re-plastering of Robben Island, where incompatible cement materials were used ${ }^{[6]}$. The Conditional Assessment Report indicates that some of the oldest buildings on the island appeared to have lost their historic 
features due to previous maintenance, which did not consider air circulation within the wall structures. The conclusion made was that most buildings' plaster and raised pointing needed to be removed, as they were suspected to be silicone and Portland cement, which are detrimental to the overall fabric. It was therefore recommended to replace the plaster and the pointing material with lime-based material which matches the original material. This is a compatibility criterion, according to the International Charters and Balkesten (2010). It is emphasized that newly introduced materials in conservation and restoration of historic structures need to match the properties of the old materials; otherwise, failure is guaranteed ${ }^{[7]}$.

Compatibility can be achieved through characterization of the original materials before searching for new repair materials ${ }^{[8]}$. A study on the charaterization of historic mortars is a requirement prior to restoration, and it includes information on aesthetic and material property compatibility (physical, chemical and mechanical) ${ }^{[5]}$. The compatibility of heritage materials is entirely dependent on the characterization of the original materials prior to restoration. Mortars and grouts used for repair of historic buildings must have properties that are compatible with the original: equal in strength, adhesion, flexibility and porosity.

\section{USE OF PORTLAND CEMENT ON LIME MORTARS}

The use of Portland cement for the repair of historical monuments as mentioned by SAHRA Bult Environment Manager is visible on the Robben Island and Castle of Good Hope, in South Africa. The island has undergone maintenance and repair works in recent years (1999 onwards)

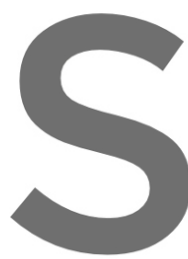
[6]. In the Island's assess consider how air circula be treated. It has been SAHRA has proposed island. The deterioration
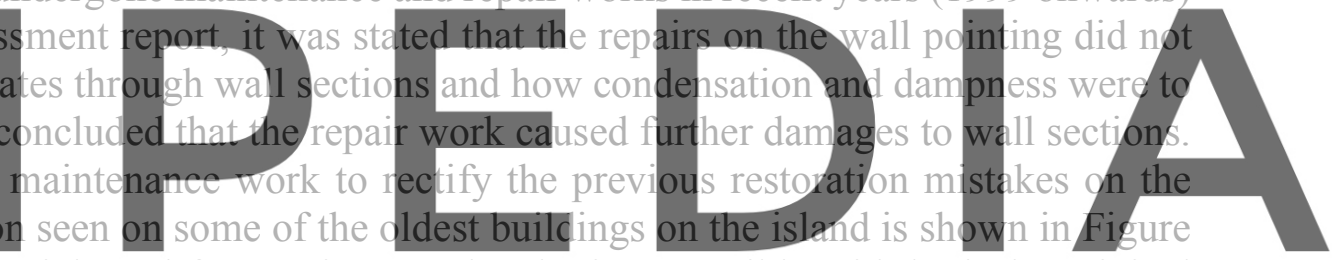

1. Regrettably, the material used for repair proved to be incompatible with both the original

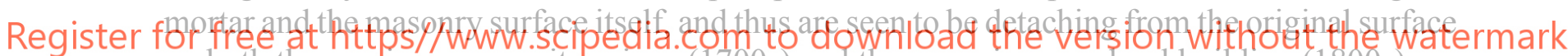
on both the maximum-security prison (1700s) and the pre-primary school building (1800s).

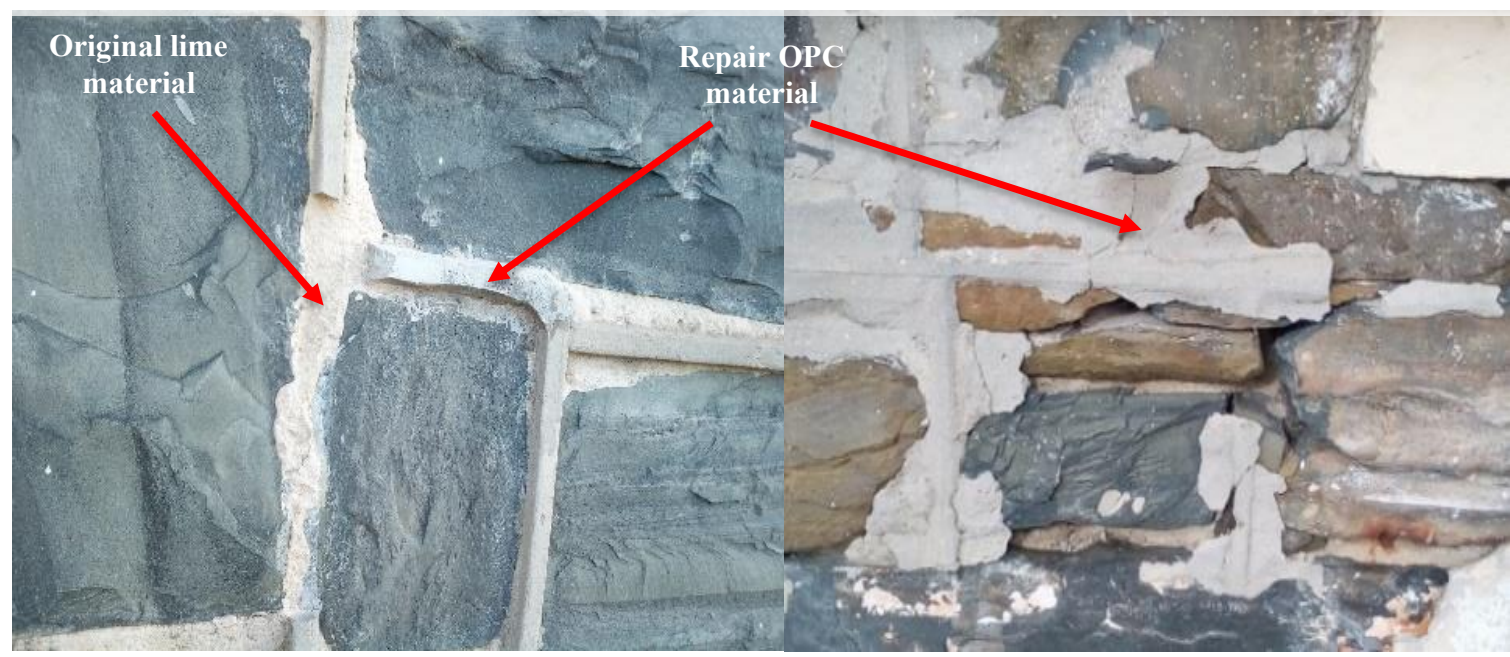

Figure 1: Deterioration and use of Portland cement on Robben Island masonry 
The disparity in materials (Figure 1) is due to the difference in properties of the lime materials that have a low modulus of elasticity and high permeability to water and water vapour ${ }^{[9]}$. The Portland cement, on the other hand, has a high soluble salts content which results in salt crystallization, large thermal expansion coefficient and low porosity ${ }^{[2]}$.

\section{CHARACTERIZATION FOR COMPATIBILITY}

Compatibility is "utilizing materials that do not have negative consequences on the original materials" ${ }^{[10]}$ and is a significant factor to assess before selection of a mortar to be used alongside suitable procedures for restoration of heritage mortars ${ }^{[11]}$. The definition is based on the properties of the original mortars, which are compared to the repair mortars and should match the original in terms of physical, mechanical and chemical properties ${ }^{[12]}$. This is to guarantee the long-term durability and strength of historical structures. It is therefore essential to conduct a detailed assessment of the material properties before carrying out repair works. Finding a compatible material to duplicate the original is an ever-greater challenge globally ${ }^{[13]}$. However, original material analysis assists in the production of a good repair mortar that matches the original ${ }^{[14]}$. The knowledge of original material properties makes it possible to foresee and predict how the historic structure will react with restoration materials applied to it.

\section{STUDY LOCATION}

The Castle of Good Hope is located in Cape Town, South Africa. It is the second fort at the

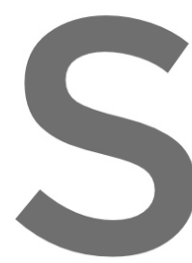
Cape, dating from 1666 to 167 It was originally located is now some distance from th stone and block mason building, experienced
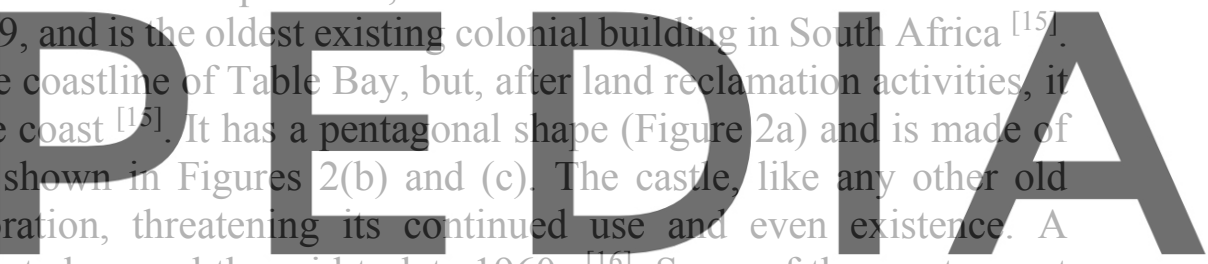

complete restoration was executed around the mid to late 1960s [16]. Some of the most recent 

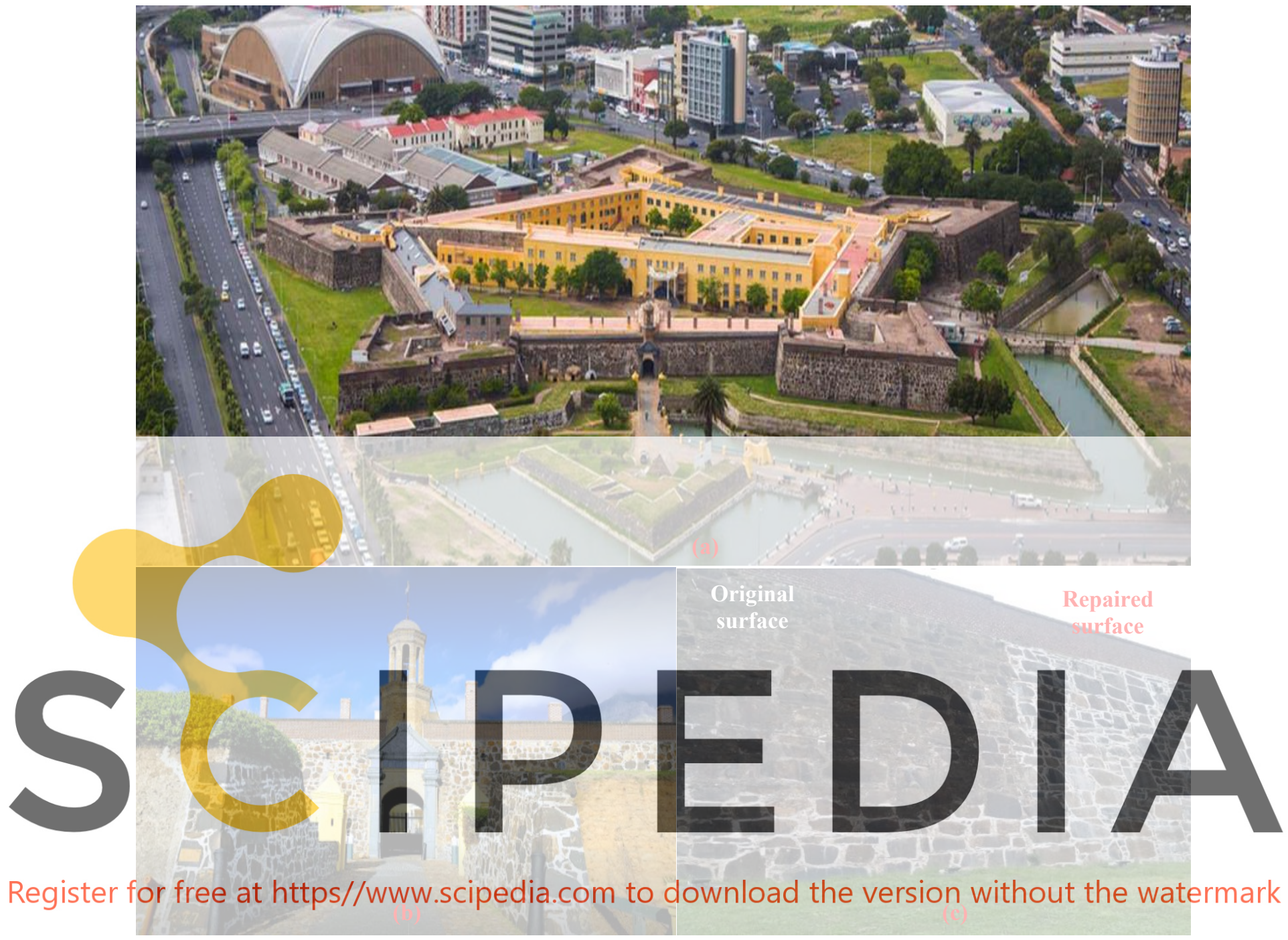

Figure 2: (a) Sky view of the Castle ${ }^{[17]}$ (b) Entrance (c) Masonry

\section{MATERIALS AND METHODS}

\subsection{Materials}

In terms of the South African National Heritage Resources Act (Act No. 25 of 1999), Section 34, a permit was granted by SAHRA before collecting the hardened mortar samples from the old kitchen wall at the Castle. An experimental approach following an on-site assessment was used for characterization of the sampled mortars. The sections that are in poor condition were identified, and their condition carefully assessed. The representative mortar samples were collected in accordance with the procedure by Ngoma ${ }^{[18]}$, using a small hammer and chisel. The description of colour, texture, sample type and location were recorded on a data sheet ${ }^{[18]}$. After collection of the in-situ materials, the samples were gently crushed using a mortar and pestle then, further physical, mineralogical and chemical analyses were carried out. 


\subsection{Methods for material analyses}

The proposed tests were performed based on non-destructive and minor destructive testing. A series of aesthetic (visual investigation and microscopic analysis), mineralogical and chemical tests (titration) were carried out. A limited quantity of samples was used due to the limitations associated with the removal of materials from historical structures. The aesthetic characterisation was undertaken to avoid harm to the original material and to preserve the aesthetic effect created by a specific colour or texture. From this survey, it was possible to distinguish between the original and the repair material. The colour difference helped to track down the possible application of the modern material on the structure. This can clearly be seen on the Castle's wall section in Figure 2 (c). The difference seen is a clue for the investigator in terms of the possible difference in materials, though this hypothesis, needs to be tested with further analysis of the materials in the laboratory. The detailed procedure for physical analysis is presented in ${ }^{[19]}$.

Additionally, mineralogical and chemical characterization (complexometric titration test using ethylenediaminetetraacetic acid) was carried out to determine the minerals present in the mortars and the type of binder and aggregates used ${ }^{[20,21]}$. For mineralogical analysis, the filtrate was investigated using reagents and indicators to determine salts present in a sample. The chemical analysis was carried out using a method that analyzes the filtrate containing oxides of elements present in a sample ${ }^{[20]}$; from that, the cementation index (CI) was calculated. The cementation of historic mortars is one of the essential aspects to investigate during the

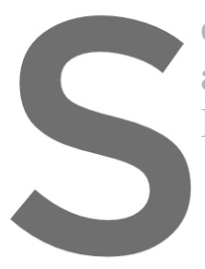
characterization process aluminium (A1), iron Equation (1) ${ }^{[22]}$.
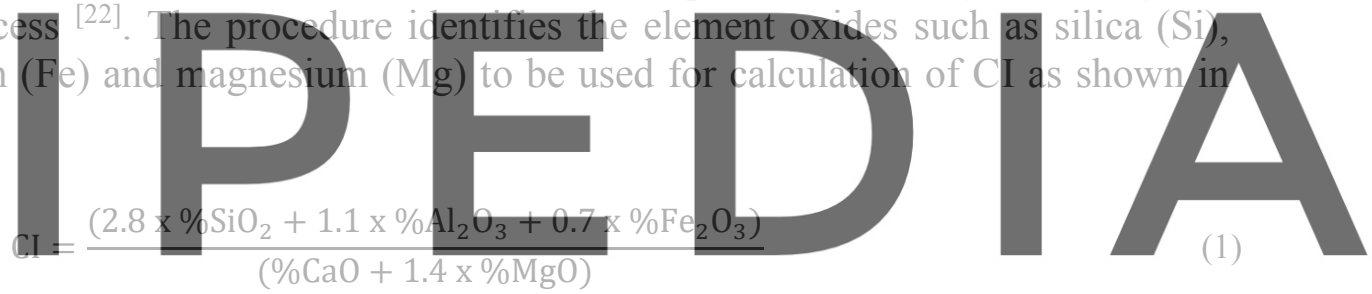

Register for free at https//www.scipedia.com to download the version without the watermark

\section{RESULTS}

The aesthetic and physical results indicated whitish lime mortars made of sand aggregates, incorporating seashell fragments having diameters between 0.5 and $25 \mathrm{~mm}$, and grey repair mortars as shown in Table 1. Part of the physical characterization results have been presented in ${ }^{[23]}$. Looking at the structure as a whole, the grey material occupies only a minor area, making it the repair material. It was evident from the masonry that the applied repair materials did not match well with the original materials. This was concluded based on the time frame of the repairs and the condition of the recently repaired areas. 
Table 1: Mortar characterization

\begin{tabular}{|c|l|l|l|l|l|}
\hline Sample ID & \multicolumn{1}{|c|}{ Color } & \multicolumn{1}{|c|}{ Cohesion } & \multicolumn{1}{c|}{ CI } & \multicolumn{1}{c|}{ Binder } & \multicolumn{1}{c|}{ Aggregates } \\
\hline SK1 & Whitish & Tough & 0,30 & Sub-hydraulic lime & Fine sand \\
\hline SK2 & Whitish grey & Tough & 0,38 & Slightly hydraulic lime & Coarse sea sand \\
\hline SK3 & Whitish yellow & Tough & 0,20 & Sub-hydraulic lime & Fine sand \\
\hline SK4 & Whitish grey & Very tough & 0,63 & Moderately hydraulic lime & Fine sand \\
\hline SK5 & Whitish & Tough & 0,46 & Slightly hydraulic lime & Fine sand \\
\hline SK6 & Cream white & Tough & 0,24 & Sub-hydraulic lime & Fine sand \\
\hline SK7 & Light yellowish & Friable & 1,18 & Natural or Portland cement & Very fine clayey sand \\
\hline SK8 & Reddish brown & Friable & 1,08 & Eminently hydraulic lime & Clayey soil \\
\hline SK9 & Yellowish orange & Friable & 2,41 & Natural or Portland cement & Clayey soil \\
\hline
\end{tabular}

The mineralogical characterization was carried out using the precipitation method, which analyzes the colour change, denoting the presence of the salt minerals in a filtrate of mortar sample, as shown in Figure 3.
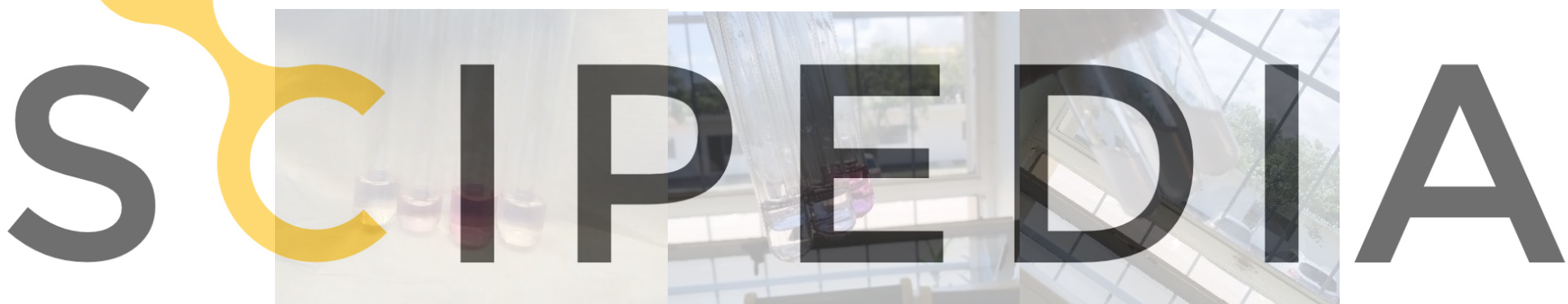

Register for free at https//www.scipedia.com to download the version without the watermark Figure 3: Precipitation of salts infiltrates of mortar

A majority of the Castle materials were high in chlorides and carbonates, while the nitrates were present in limited quantities for both the binder enriched materials (Particles $<0.063 \mathrm{~mm}$ ) and the aggregates (Particles $>0.063 \mathrm{~mm}$ ) as indicated in Tables 2 and 3. 
Table 2: Salt content in mortar (Particles $<0.063 \mathrm{~mm}$ )

\begin{tabular}{|c|c|c|c|c|c|}
\hline Sample ID & Sulfates & Chlorides & Nitrites & Nitrates & Carbonates \\
\hline SK1 & +++ & ++ & \pm & - & + \\
\hline SK2 & +++ & +++ & + & - & +++ \\
\hline SK3 & ++ & +++ & +++ & + & +++ \\
\hline SK4 & ++ & ++ & + & - & +++ \\
\hline SK5 & \pm & +++ & + & \pm & +++ \\
\hline SK6 & + & +++ & - & - & +++ \\
\hline SK7 & +++ & ++ & - & - & ++ \\
\hline SK8 & \pm & ++ & - & + & \pm \\
\hline SK9 & \pm & ++ & \pm & - & + \\
\hline
\end{tabular}

Table 3: Salt content in mortar (Particles $>0.063 \mathrm{~mm}$ )
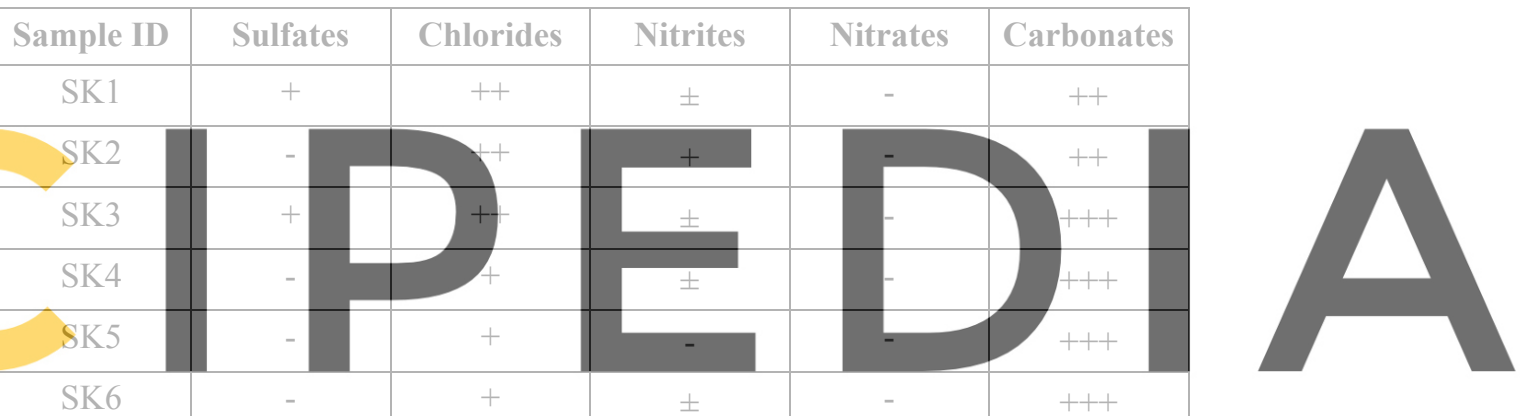

Register for free at httpss //www.seipedia.com to download the version without the watermark

\begin{tabular}{|l|l|l|l|l|l|}
\hline SK8 & \pm & ++ & \pm & - & - \\
\hline SK9 & \pm & \pm & + & \pm & + \\
\hline
\end{tabular}

Where:

- Indicates the absence of an ion

\pm Indicates the presence of an ion at the limit of perceptibility

+ Indicates the presence of an ion

++ Indicates the presence of an ion in notable quantity

+++ Indicates the presence of an ion as a principal component ${ }^{[27]}$.

\section{CONCLUSIONS}

- Even though characterization of heritage mortars for compatible and sustainable restoration is proven to yield repairs which would last for decades, it has received less attention in Africa. Thus, restoration of historic masonries is carried out using the materials that do not match the original. 
- A further study to analyze the mechanical properties would be a worthwhile investment. The study addressing general material analysis other than mortars could yield a detailed recommendation on the repair of heritage buildings that will better suit the original materials.

- $\quad$ As is evident on the surfaces of the Castle and Robben Island, Portland cement fails on the restoration of historic lime mortars. Therefore, further investigation into the alternative repair materials that would match the original is underway. Such materials need to have similar or better properties than the original.

Acknowledgements: The authors wish to acknowledge the financial support from the government of Lesotho and the Cape Peninsula University of Technology for this project. The permission to sample materials from the Castle of Good Hope and Robben Island by the South African Heritage Resources Agency and the Sites' management is appreciated. A special thanks to the laboratory assistance by Ms Dlanjwa and Ms Mathobela from the Department of Chemistry at the Cape Peninsula University of Technology. I am also thankful to the reviewer for improving the quality of the paper.

\section{REFERENCES}

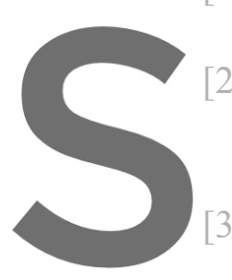

[1] Feilden, B. M. Conservation of Historic Buildings. 3rd edition, Architectural press,

$$
\text { Elsevier (2003). }
$$

2] Marini, A., Comine mortar slab for compatib and Building Mate

Gleize, P.J.P., Mott mortars from Santa Catarind 346. Town; South Africa (2018).

[5] Apostolopoulou, M., Aggelakopoulou, E., Siouta, L., Bakolas, A., Douvika, M., Asteris, P. G. and Moropoulou, A. A methodological approach for the selection of compatible and performable restoration mortars in seismic hazard areas. Construction and Building Materials (2017) 155: 1-14.

[6] Conditional Assessment of Buildings on Robben Island: Outline Description of Material Testing Required. 2018. Cape Town, South Africa. Available at: https://sahris.sahra.org.za (accessed in March 2019).

[7] Balksten, K. Understanding Historic Mortars and their Variations - a Condition for Performing Restorations with Traditional Materials. 2nd Historic Mortars Conference HMC2010 and RILEM TC 203-RHM Final Workshop 22-24 September 2010, Prague, Czech Republic (2010).

[8] Hormes, J., Diekamp, A., Klysubund, W., Bovenkamp, G. L. and Börste, N. The characterization of historic mortars: A comparison between powder diffraction and synchrotron radiation-based X-ray absorption and X-ray fluorescence spectroscopy. Microchemical Journal (2016) 125: 190-195. 
[9] Palomo, A., Blanco-Varela, M. T., Martinez-Ramirez, S., Puertas F. and Fortes, C.

Historic Mortars: Characterization and Durability. New Tendencies for Research (2014).

[10] Isebaert, A., Van Parys, L. and Cnudde, V. Composition and compatibility requirements of mineral repair mortars for stone - A review. Construction and Building Materials, (2014) 59: 39-50.

[11] Bertolini, L., Carsana, M., Gastaldi, M., Lollini, F. and Redaelli, E. Binder characterisation of mortars used at different ages in the San Lorenzo church in Milan. Material Characterization (2013) 80: 9-20.

[12] Cizer, Ö., Schueremans, L., Serre, G., Janssens, E. and Van Balen, K. Assessment of the Compatibility of Repair Mortars in Restoration Projects. Advanced Materials Research, (2010) 133-134: 1071-1076.

[13] Deshpande, U. L. Repair, restoration and strengthening of building. International Journal of I Innovations in Engineering Research and Technology (2017) 4(3): 121 - 124.

[14] Gulzar, S., Chaudhry, M. N., Burg J. P. and Saeed S. A. Characteristics of Ancient Mortars and Plasters from the Archaeological Site of Akbari-Serai (Pakistan). Journal of Chemistry (2013) 25(15): 8484-8488.

[15] Castle of Good Hope. 2018. Available at https://castleofgoodhope.co.za (accessed in September 2018).

[16] Gilbert, C. The Castle of Good Hope: An Examination of Controversies and Conflicting Perceptions - A Case Study in Public History. An Honours degree thesis, University of Cape Town, South Africa (1994)

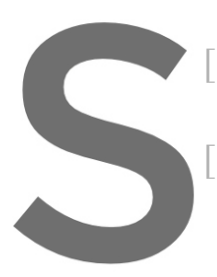

17] Sky view of the
(accessed in Janua
18] Ngoma, A. M. K.
Cultural Heritage
University of Dar-
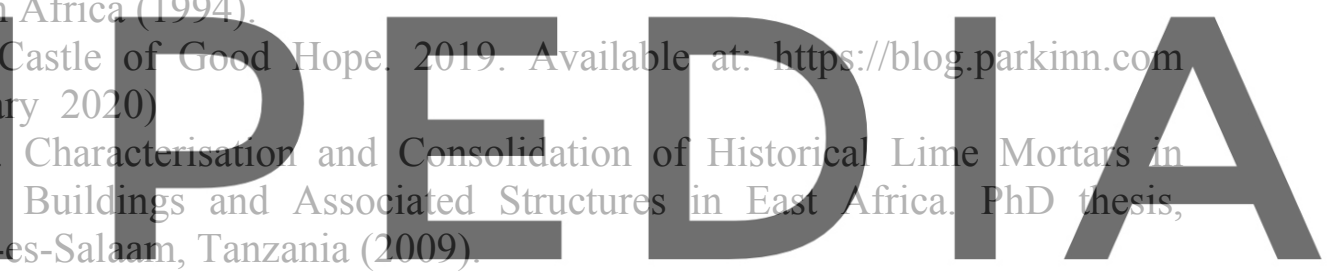

[19] Groot, C.J.W.P, Ashall, G.J., Hughes, J.J. and Bartos, P.J.M. Characterisation of old

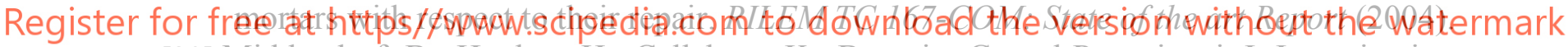

[20] Middendorf, B., Hughes, H., Callebaut, K., Baronio, G. and Papayianni, I. Investigation Methods for the Characterisation of Historic Mortars, Part 2: Chemical Characterisation. Materials and Structures (2005) 38: 771-780.

[21] Teutonico, J. M. ICCROM Arc laboratory manual for architectural conservators. Rome, Italy, 1988.

[22] Brosnan, D. A. Characterization and Degradation of Masonry Mortar in Historic Brick Structures. Hindawi Publishing Corporation, Journal of Structures, volume 2014, Article ID: 85987 (2014), pp. 1-7.

[23] Loke, M.E., Kumar, P. and Haldenwang, R. Physical characterization of heritage mortars for restoration interventions. IEEE 10th International Conference on Mechanical and Intelligent Manufacturing Technologies (ICMIMT 2019), Cape Town: South Africa, 2022 January 2020 (Presented). 